\title{
Resistência ao cisalhamento submetido ao tráfego de um trator agrícola ${ }^{1}$
}

\author{
DA/FAFEID, CEP 39100-000, Diamantina, MG. E-mail: jackson_barbosa@hotmail.com \\ 2 Departamento de Ciência do Solo, UFLA, CEP 37200-000, Lavras, MG. \\ 3 DEA/UFV, CEP 36571-000, Viçosa, MG. Fone: (31) 3899-1879. E-mail: Ibaiao@mail.ufv.br
}

Jackson A. Barbosa', Moacir de S. Dias Junior ${ }^{2}$, Luciano B. Vieira ${ }^{3}$, Gutemberg P. Dias ${ }^{3}$

Protocolo 97 - 27/5/2003 - Aprovado em 19/2/2004

\begin{abstract}
Resumo: A principal causa da compactação dos solos agrícolas é o tráfego de tratores e máquinas, em sua maioria montados sobre rodados pneumáticos. Quando um rodado se desloca sobre uma superfície são geradas tensões perpendiculares e tangenciais a ela, as quais, denominadas ainda tensões normal e cisalhante, são transmitidas à massa de solo, a partir da área de contato rodadosolo. Este trabalho teve como objetivo avaliar o efeito do tráfego de um trator agrícola, em diferentes condições operacionais, nos parâmetros curva tensão-deformação, tensão cisalhante máxima e deformação máxima de um Argissolo Vermelho-Amarelo. O delineamento experimental foi inteiramente casualizado, em esquema fatorial $2 \times 2 \times 3$, constituído por dois tipos de rodados pneumáticos agrícolas (rodados de configuração diagonal e configuração radial), duas pressões de insuflagem dos rodados (168 e $98 \mathrm{kPa}$ ) e três níveis de patinagem dos rodados $(0,10,0,20$ e $0,30 \mathrm{~m} \mathrm{~m}^{-1}$ ), com quatro repetições, perfazendo o total de quarenta e oito unidades (ou parcelas) experimentais. Os ensaios de cisalhamento direto foram realizados em amostras indeformadas, usando-se uma prensa de cisalhamento da marca Ele International. Os resultados mostraram que o tráfego do trator agrícola, em condições elevadas de pressão de insuflagem e patinagem, causa deslocamento das curvas tensão-deformação para regiões de maiores tensões cisalhantes, podendo ensejar degradação da estrutura do solo.
\end{abstract}

Palavras-chave: compactação de solos agrícolas, tráfego de tratores, curvas tensão-deformação

\section{Shear strength of a Red Yellow Argissolo under agricultural tractor traffic}

\begin{abstract}
The main cause of the compaction of agricultural soils, is the traffic of tractors and machines, with pneumatic tires. When one tire roll on a soft soil, normal and tangencial strengths are applied to it. The tire-soil interface defines characteristics of transmission to the soil mass of these strengths. The main objective of this work was to assess soil reology due to agricultural traffic. The experimental design was a completly randomized (factorial), consisting of two types of tires cross-ply and radial, two tire pressures (168 and $98 \mathrm{kPa}$ ), and, three levels of slipage $\left(0.10,0.20\right.$ and $\left.0.30 \mathrm{~m} \mathrm{~m}^{-1}\right)$, with four replications. The assessment of direct shear strength was carried out on soil samples, using a universal strength machine of the Ele International. The results showed that traffic of agricultural tractor, rolling in over pressured conditions and high motion reduction due to slipage, cause displacement of the tension-deformation curves towards regions of higher shear tensions, allowing potential soil structure degradation.
\end{abstract}

key words: compaction of agricultural soils, tractor traffic, tension-deformation curves

\section{INTRODUÇÃO}

A principal causa da compactação dos solos agrícolas é o tráfego de tratores e máquinas, em sua maioria montados sobre rodados pneumáticos (Barbosa, 2002). Quando um rodado se desloca sobre uma superfície, são geradas tensões perpendiculares e tangenciais a ela. Essas tensões, também denominadas tensões normal e cisalhante, são transmitidas à massa de solo, a partir da área de contato rodado-solo.

O desenvolvimento de relações empíricas que permitam o projeto de rodados mais eficientes pode ser conseguido a partir de um melhor entendimento das tensões e forças que atuam na interface rodado-solo (Wood \& Burt, 1987).

A magnitude das tensões exercidas na interface rodadosolo ações verticais da capacidade de suporte de carga do 
solo; e, ações tangenciais, que possibilitam que o rodado desenvolva tração, segundo sua capacidade de suportar a tensão tangencial (cisalhante) aplicada. A capacidade de suporte ao cisalhamento de um solo é proporcional a carga vertical aplicada, sendo aceito, de forma geral o critério de ruptura de Coulomb (Upadhyaya et al., 1994).

A determinação de parâmetros como curva tensãodeformação, tensão cisalhante máxima e deformação máxima, coesão e ângulo de atrito interno do solo se faz em laboratório com uso de equipamentos como prensa de cisalhamento direto e triaxial. Para predizer o comportamento de um veículo em terreno natural, se realizam ensaios in situ com placas retangulares ou anilhos de corte, com diferentes cargas verticais, inserindo a placa no terreno ou girando o anilho até que o solo se rompa. Assim, se obtêm as curvas tensãodeformação, para as condições de carga normal e tangencial ao solo (Uphadyaya et al., 1994).

Nos solos friccionais, a tensão cisalhante alcança um valor máximo para uma deformação relativamente pequena, para depois descender e estabilizar. Nos solos coesivos pode não existir o pico, e a curva crescer continuamente para passar sem interrupção de um comportamento elasto-plástico ao plástico (Wiermann et al., 1999).

Em um experimento para avaliar o estado de tensão induzido a um solo agrícola classificado como "Norfolk sandy loam", Wiermann et al. (1999) avaliaram o efeito da carga dinâmica e do número de passadas nas tensões e deformações impostas ao solo. Três diferentes cargas dinâmicas foram aplicadas ao solo, em duas passadas, e a um nível constante de velocidade de avanço de $0,15 \mathrm{~m} \mathrm{~s}^{-1}$, e patinagem do rodado de $0,10 \mathrm{~m} \mathrm{~m}^{-1}$. Pôde-se observar que a razão entre a tensão cisalhante e a tensão normal média, aumentaram significativamente quando ocorreu a segunda passada do rodado. Esse aumento é devido, basicamente, ao aumento da tensão cisalhante. Os autores citam que os valores de tensão apresentados são valores subestimados, devido ao deslocamento vertical e horizontal dos sensores.

Para avaliar a tensão cisalhante imposta por um rodado pneumático 18,4 R 38 em solo agrícola, Wood et al. (1991) realizaram testes em condição de solo compactado e solto, com quatro níveis de cargas dinâmicas impostas ao rodado. As informações obtidas mostraram que o rodado desenvolveu tensões cisalhantes, ao longo da largura de contato, de forma mais uniforme em solo solto, comparativamente a condição de solo compactado. Um aumento em carga dinâmica resultou em aumento significativo da tensão cisalhante no centro da garra. Maiores níveis de tensões cisalhantes foram obtidos em solo compactado, proporcionalmente ao solo solto.

Em estudo conduzido por Way et al. (1995), transdutores de estado de tensão foram instalados em dois tipos diferentes de solos agrícolas, com finalidade de avaliar o comportamento do estado de tensões imposto aos solos, como função da altura das garras de um rodado pneumático de uso agrícola. $\mathrm{O}$ experimento foi montado no "National Soil Dynamics Laboratory", Auburn, Al, USA, em caixas de solo. Os solos utilizados foram: "Norfolk sandy loam", e, "Decatur clay loam soil". Três transdutores de estado de tensão foram instalados em diferentes profundidades, para medir as tensões abaixo do rodado. Os resultados de Way et al. (1995) possibilitaram concluir que, para as condições experimentais impostas, não houve efeito da altura das garras na distribuição de tensões no solo.

A instalação de transdutores de estado de tensão tridirecional em garras de um rodado agrícola foi feita por Jun et al. (1998), com o objetivo de avaliar a distribuição de tensões transversais nas garras. Os transdutores foram instalados em três distintas posições sendo, extremidade interna, extremidade externa e, ponto intermediário entre as duas. $\mathrm{O}$ rodado foi operado em duas condições de carga dinâmica $(9,3$ e 14,2 kN), e duas condições de pressão de insuflagem (59 e $157 \mathrm{kPa})$. Os dados do estudo de Jun et al. (1998) foram coletados na caixa de solo pertencente a "Obihiro University of Agriculture and Veterinary Medicine", Obihiro, Japão. Como resultados, Jun et al. (1998) concluíram que aumentos de carga dinâmica e de pressão de insuflagem aumentaram os níveis de tensão; o padrão de distribuição de tensões refletiu com maior significância o efeito da pressão de insuflagem, comparativamente à carga dinâmica; a máxima tensão normal ocorreu próxima a extremidade interna do rodado, quando o mesmo se encontrava em condição de alta pressão de insuflagem; a máxima tensão tangencial se deu próxima a extremidade interna do rodado, reduzindo no sentido da extremidade externa.

Com o objetivo de avaliar as tensões impostas a um solo agrícola, em diferentes profundidades, Sumali et al. (2000) projetaram e testaram uma lâmina de aço, atuando no solo de forma vertical. "Strain gauges" foram montados na parte posterior da lamina, registrando as deformações durante seu deslocamento. Para validar a relação sinal de saída versus tensão aplicada ao sensor, obtida em laboratório, Sumali et al. (2000) montaram experimento em solo franco argilo siltoso não trabalhado. Quatro passadas de dez metros foram realizadas, com a lâmina de aço se deslocando a velocidade de $1 \mathrm{~km} \mathrm{~h}^{-1}$, assim como leituras de resistência à penetração.

Uma das informações de maior interesse do trabalho de Sumali et al. (2000), são os mapas de resistência mecânica do solo. Esses mapas, possibilitam, determinar com grande exatidão a profundidade em que ocorrem um grau de compactação prejudicial ao desenvolvimento cultural, e a distribuição dessa compactação em uma determinada área. Como resultados, os autores concluíram que o sistema de determinação de tensões desenvolvido apresentou desempenho satisfatório, quando se compararam valores de campo com valores determinados em laboratório; observou-se que a resistência do solo à penetração apresentou boa correlação com a resistência imposta à lâmina de aço.

Enfim, este trabalho teve como objetivo avaliar o efeito do tráfego de um trator agrícola, em diferentes condições operacionais, nos parâmetros curva tensão-deformação, tensão cisalhante máxima e deformação máxima de um Argissolo Vermelho-Amarelo.

\section{MATERIAL E MÉTODOS}

O estudo foi conduzido em um Argissolo Vermelho-Amarelo, localizado no Campus da Universidade Federal de Viçosa, MG, com latitude de $20^{\circ} 45^{\prime} 20^{\prime \prime}$ Sul, longitude de 42 ${ }^{\circ} 52^{\prime} 40^{\prime \prime}$ Oeste e altitude média de $650 \mathrm{~m}$. Dois meses antes da instalação do 
experimento, a área foi subsolada, sendo eliminada $60 \%$ da cobertura vegetal.

As análises físicas do solo foram realizadas no Laboratório de Geotecnia do Departamento de Engenharia Civil da Universidade Federal de Viçosa (Tabela 1).

Tabela 1. Caracterização física do Argissolo Vermelho-Amarelo na profundidade de 0 a $0,15 \mathrm{~m} *$

\begin{tabular}{llc}
\multicolumn{1}{c}{ Parâmetro analisado } & Unidade & Valor* \\
\hline Teor de argila & $\mathrm{kg} \mathrm{kg}^{-1}$ & 0,68 \\
Teor de areia & $\mathrm{kg} \mathrm{kg}^{-1}$ & 0,15 \\
Teor de silte & $\mathrm{kg} \mathrm{kg}^{-1}$ & 0,17 \\
\hline Limite de liquidez & $\mathrm{kg} \mathrm{kg}^{-1}$ & 0,57 \\
Limite de plasticidade & $\mathrm{kg} \mathrm{kg}^{-1}$ & 0,42 \\
Limite de contração & $\mathrm{kg} \mathrm{kg}^{-1}$ & 0,28 \\
Índice de friabilidade & $\mathrm{kg} \mathrm{kg}^{-1}$ & 0,14 \\
\hline Densidade do solo & $\mathrm{Mg} \mathrm{m}^{-3}$ & 1,32 \\
Densidade de partículas & $\mathrm{Mg} \mathrm{m}^{-3}$ & 2,73 \\
\hline
\end{tabular}

* Média de três repetições

O delineamento experimental foi inteiramente casualizado, em esquema fatorial $2 \times 2 \times 3$, constituído por dois tipos de rodados pneumáticos agrícolas (rodados de configuração diagonal e configuração radial), duas pressões de insuflagem dos rodados $(168$ e $98 \mathrm{kPa})$, e, três níveis de patinagem dos rodados $(0,10$; 0,20 e $0,30 \mathrm{~m} \mathrm{~m}^{-1}$ ), com quatro repetições, perfazendo um total de quarenta e oito unidades (ou parcelas) experimentais.

Cada parcela (ou unidade) experimental foi trafegada por um trator agrícola Massey Fergusson 5290. O trator foi operado com rodados diagonais PIRELLI TM 95 18,4-32 no eixo traseiro e PIRELLI TM 95 14,9-24 no eixo dianteiro, e rodados radiais PIRELLI TM 700 510/70 32 no eixo traseiro e PIRELLI TM 200 14,9 R 24 no eixo dianteiro. Os rodados foram inflados a 98 e $168 \mathrm{kPa}$ de pressão.

Para se obter as patinagens dos rodados de 0,10 ( $\pm 25 \%)$, $0,20( \pm 25 \%)$ e $0,30( \pm 25 \%) \mathrm{m} \mathrm{m}^{-1}$, foram impostas cargas à barra de tração pela adoção de um "trator de frenagem" Valmet 110. Em cada unidade experimental, o trator se deslocou $40 \mathrm{~m}$, em segunda marcha reduzida, e $1.750 \mathrm{r} \mathrm{min}^{-1}$ de rotação no motor, correspondendo à velocidade de $1,32 \mathrm{~m} \mathrm{~s}^{-1}$. A rotação e marcha do trator de frenagem foram alteradas para obtenção dos diferentes níveis de patinagem.

Ao final de cada ensaio, e no solo trafegado pelos rodados dianteiro e traseiro direito, foram coletadas amostras de solo indeformadas e deformadas para determinação de propriedades físicas e da curva tensão-deformação. A amostragem foi realizada na profundidade de $0-0,05 \mathrm{~m}$, com três repetições.

Os ensaios de cisalhamento direto foram realizados em amostras indeformadas, usando uma prensa de cisalhamento da marca Ele International (Figura 1). Os ensaios foram realizados a uma velocidade constante de avanço da máquina de $2 \mathrm{~mm} \mathrm{~s}^{-1}$, e tensão normal aplicada à amostra de $150 \mathrm{kPa}$. A coleta de dados ocorreu a cada $30 \mathrm{~s}$ e, após cada ensaio, a curva tensão-deformação do solo foi obtida plotando-se a deformação horizontal da amostra no eixo das abscissas, versus tensão cisalhante no eixo das ordenadas.

A análise estatística consta de análise de variância, onde cada combinação de níveis de fatores foi estimada por um

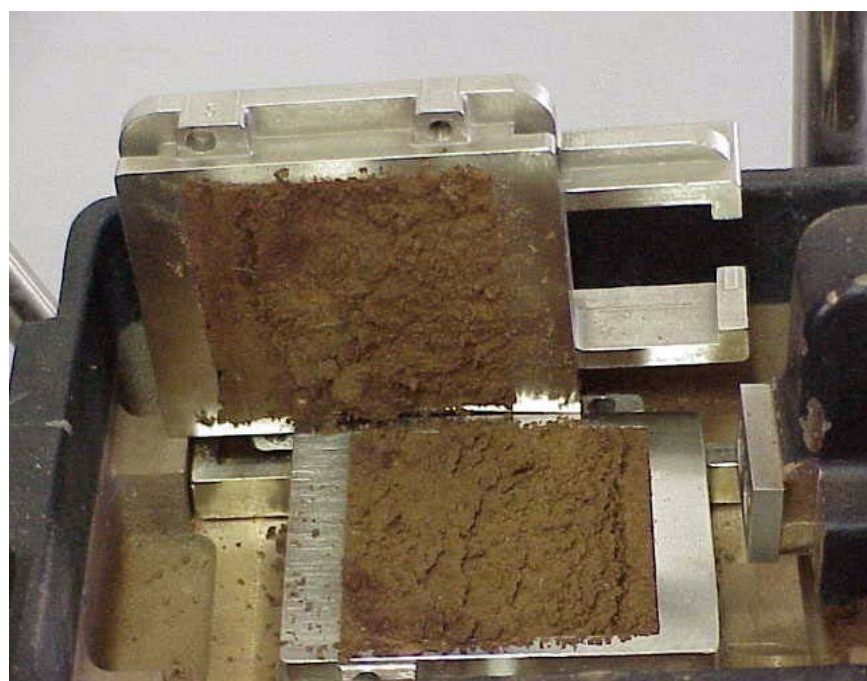

Figura 1. Prensa para cisalhamento direto (Departamento de Ciência do Solo - Universidade Federal de Lavras) e amostra de solo cisalhada (Rocha \& Dias Junior, 2000)

intervalo de confiança, seguindo a distribuição t de Student, ao nível de probabilidade de $95 \%$.

\section{RESULTADOS E DISCUSSÃO}

A Figura 2 mostra as curvas tensão-deformação do solo antes e após o tráfego do trator agrícola acoplado com rodados diagonais, com $168 \mathrm{kPa}$ de pressão de insuflagem e patinagens de $0,10,0,20$ e $0,30 \mathrm{~m} \mathrm{~m}^{-1}$. Na pressão de insuflagem de $168 \mathrm{kPa}$ (A), as curvas se deslocaram para regiões de maiores tensões cisalhantes aumentando, desta forma, a resistência ao cisalhamento do solo, o que pode causar maior demanda energética em operações de preparo de solo.

Ao se reduzir a pressão dos rodados diagonais para $98 \mathrm{kPa}$ (Figura 2 B), observa-se que na patinagem de $0,10 \mathrm{~m} \mathrm{~m}^{-1}$ não houve deslocamento da curva tensão-deformação para regiões de maiores tensões cisalhantes mas, sim, nas demais condições de patinagem, mostrando a necessidade da correta adequação trator-implemento às condições de trabalho, de forma a minimizar a patinagem dos rodados motrizes e, conseqüentemente, a degradação dos solos agrícolas.

Nas Figuras 3 A e B tem-se as curvas tensão-deformação do solo antes e após o tráfego do trator agrícola acoplado com rodados radiais, com 168 e $98 \mathrm{kPa}$ de pressão de insuflagem, respectivamente, e patinagens de $0,10,0,20$ e $0,30 \mathrm{~m} \mathrm{~m}^{-1}$. De forma semelhante aos rodados diagonais, os rodados radiais na pressão de insuflagem de $168 \mathrm{kPa}$ deslocaram as curvas tensão-deformação para regiões de maiores tensões cisalhantes, em todas as condições de patinagem (A). Ao se reduzir a pressão de insuflagem dos rodados para $98 \mathrm{kPa}$, também de forma semelhante aos rodados diagonais, não houve deslocamento da curva tensão-deformação para regiões de maiores tensões cisalhantes na patinagem de $0,10 \mathrm{~m} \mathrm{~m}^{-1}$, ocorrendo este deslocamento nas demais condições de patinagem (B).

A Tabela 2 mostra os valores de tensão cisalhante máxima e deformação máxima das amostras de solo, em função do tipo e da condição operacional dos rodados. 
A.

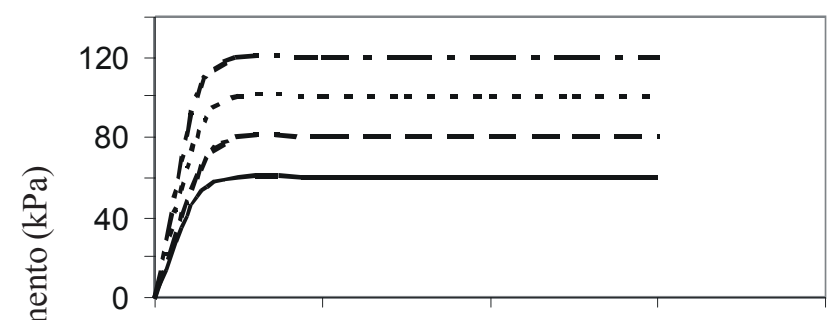

B.

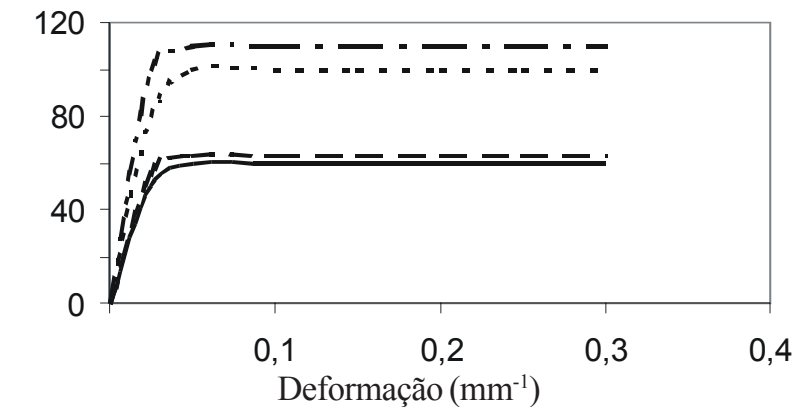

- Antes $\quad-0,1 \quad \cdots=0,2 \quad-\quad-0,3$

Figura 2. Curvas tensão-deformação do solo antes e após o tráfego dos rodados diagonais com 168 (A) e 98 (B) $\mathrm{kPa}$ de pressão de insuflagem, para patinagens de $0,10,0,20 \mathrm{e} 0,30 \mathrm{~m} \mathrm{~m}^{-1}$

Os rodados inflados a $168 \mathrm{kPa}$ não indicaram diferença significativa entre os valores de tensão cisalhante máxima antes e após o tráfego a $0,10 \mathrm{~m} \mathrm{~m}^{-1}$ de patinagem mas, sim, diferença significativa para as demais patinagens, independente do tipo de rodado (Tabela 2). Ao se reduzir a pressão de insuflagem para $98 \mathrm{kPa}$, os rodados não mostraram diferença significativa ao se compará-los antes e após o tráfego a 0,10 e $0,20 \mathrm{~m} \mathrm{~m}^{-1} \mathrm{de}$ patinagem, mas para patinagem de $0,30 \mathrm{~m} \mathrm{~m}^{-1} \mathrm{sim}$, indicando que a adequação da pressão de insuflagem do rodado às condições de trafegabilidade do solo agrícola é mais importante que o tipo de rodado utilizado.

Tabela 2. Valores de tensão cisalhante máxima e deformação máxima das amostras de solo*

TR/PI Patinagem $\left(\mathrm{m} \mathrm{m}^{-1}\right)$ TCmáx $(\mathrm{kPa})$ Dmáx $\left(\mathrm{m} \mathrm{m}^{-1}\right)$

\begin{tabular}{lcrl}
\hline & Antes & $83 \mathrm{~B}$ & $0,150 \mathrm{~B}$ \\
Rodados & 0,10 & $103 \mathrm{~B}$ & $0,172 \mathrm{~B}$ \\
diagonais $168 \mathrm{kPa}$ & 0,20 & $129 \mathrm{~A}$ & $0,223 \mathrm{~A}$ \\
& 0,30 & $139 \mathrm{~A}$ & $0,235 \mathrm{~A}$ \\
\hline \multirow{2}{*}{ Rodados } & Antes & $83 \mathrm{~B}$ & $0,150 \mathrm{~B}$ \\
diagonais $98 \mathrm{kPa}$ & 0,10 & $85 \mathrm{~B}$ & $0,150 \mathrm{~B}$ \\
& 0,20 & $101 \mathrm{~B}$ & $0,181 \mathrm{~B}$ \\
& 0,30 & $115 \mathrm{~A}$ & $0,216 \mathrm{~A}$ \\
\hline & Antes & $83 \mathrm{~B}$ & $0,150 \mathrm{~B}$ \\
Rodados & 0,10 & $103 \mathrm{~B}$ & $0,170 \mathrm{~B}$ \\
radiais $168 \mathrm{kPa}$ & 0,20 & $131 \mathrm{~A}$ & $0,200 \mathrm{~A}$ \\
& 0.30 & $140 \mathrm{~A}$ & $0.240 \mathrm{~A}$ \\
\hline & Antes & $83 \mathrm{~B}$ & $0,150 \mathrm{~B}$ \\
Rodados & 0,10 & $85 \mathrm{~B}$ & $0,150 \mathrm{~B}$ \\
radiais $98 \mathrm{kPa}$ & 0,20 & $98 \mathrm{~B}$ & $0,178 \mathrm{~B}$ \\
& 0,30 & $117 \mathrm{~A}$ & $0,223 \mathrm{~A}$ \\
\hline
\end{tabular}

* TR - Tipo de Rodado; PI - Pressão de Insuflagem; TCmáx - Tensão Cisalhante máxima; Dmáx Deformação máxima. Em cada coluna, para cada fator, médias seguidas de mesma letra maiúscula não diferem entre si, pelo teste de Tukey a $5 \%$.

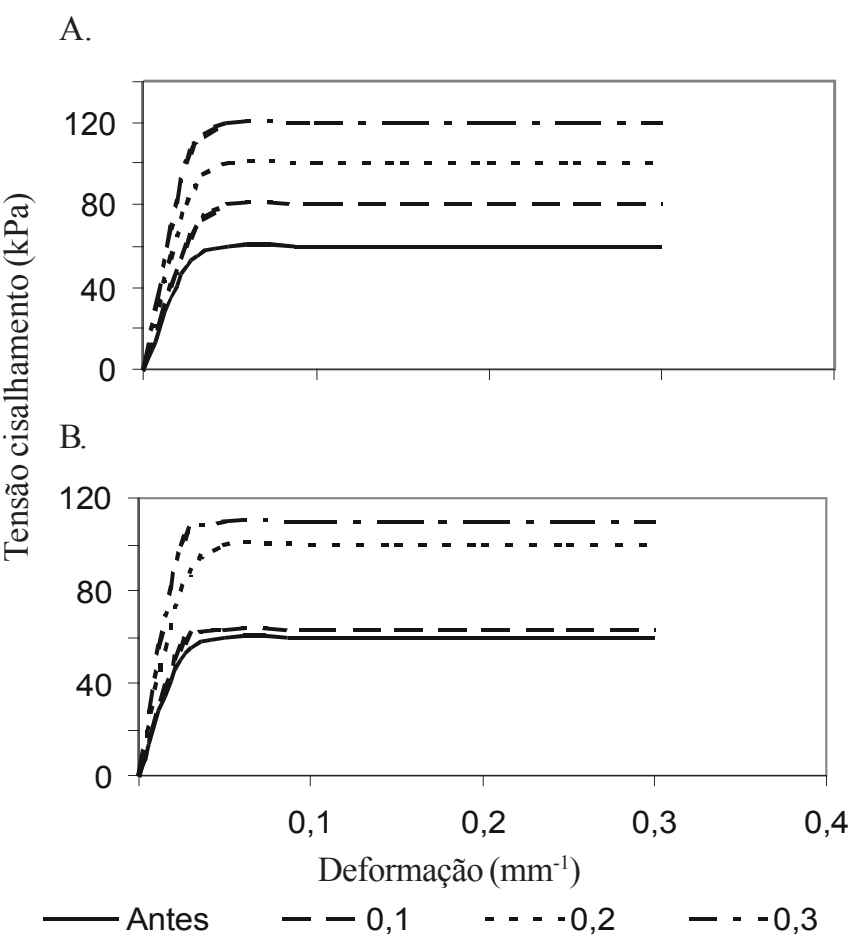

Figura 3. Curvas tensão-deformação do solo antes e após o tráfego dos rodados radiais com 168 (A) e 98 (B) $\mathrm{kPa}$ de pressão de insuflagem, para patinagens de $0,10,0,20$ e $0,30 \mathrm{~m} \mathrm{~m}^{-1}$

Os valores de deformação máxima das amostras de solo indicaram comportamento semelhante aos valores de tensão cisalhante máxima (Tabela 2), mostrando assim a necessidade de se adequar corretamente a pressão de insuflagem e a patinagem dos rodados, para causar mínima degradação à estrutura do solo.

\section{CONCLUSÕES}

1. Quando inflados a $168 \mathrm{kPa}$ de pressão, os rodados pneumáticos avaliados deslocaram as curvas tensãodeformação para regiões de maiores tensões cisalhantes, independente do nível de patinagem,

2. Quando inflados a $98 \mathrm{kPa}$ de pressão, a patinagem de $0,10 \mathrm{~m} \mathrm{~m}^{-1}$ não apresentou efeito em deslocar a curva tensãodeformação para regiões de maiores tensões cisalhantes,

3. Independente do tipo de rodado, na pressão de insuflagem de $168 \mathrm{kPa}$ maiores valores de tensão cisalhante máxima e deformação do solo foram atribuídos às patinagens de 0,20 e $0,30 \mathrm{~m} \mathrm{~m}^{-1}$,

4. Na pressão de insuflagem de $98 \mathrm{kPa}$, os maiores valores de tensão cisalhante máxima e deformação do solo são atribuídos à patinagem de $0,30 \mathrm{~m} \mathrm{~m}^{-1}$.

\section{LITERATURA CITADA}

Barbosa, J.A. Efeito do tráfego de rodados pneumáticos em propriedades mecânicas de um argissolo vermelho-amarelo. Viçosa: UFV, 2002. 119p. Tese Doutorado 
Jun, H.; Kishimoto, T.; Way, T.R.; Taniguchi, T. Threedirectional contact stress distribution for a pneumatic tractor tire in soft soil. Transactions of the ASAE, St. Joseph, v.41, n.5, p.1237-1242, 1998.

Rocha, W.W., Dias Junior, M.S. Avaliação da resistência ao cisalhamento de cinco solos da região de Lavras, MG. In:Reunião Brasileira de Manejo e Conservação do Solo e da Água, 8, 2000, Ilhéus, BA. CD..., 2000.

Sumali, A.; Adamchuk, V.I; Morgan, M. Application of a strain gauge array to estimate soil mechanical impedance on-thego. In.: Borém, A.; Giúdice, M.P.; Queiroz, D.M.; Mantovani, E.C.; Ferreira, L.R.; Vale, F.X.R; Gomide, R.L. Agricultura de precisão. Viçosa, 2000. 467p.: il.

Upadhyaya, S.K.; Chancellor,W.J.; Perumpral, J.V.; Schafer, R.L.; Gill, W.R..; VandenBerg, G.E. Advances in soil dynamics. St. Joseph, American Society of Agricultural Engineers, 1994. 313p.: il.
Way, T.R.; Bailey, A.C.; Raper, R.L.; Burt, E.C. Tire lug height effects on soil stresses and bulk density. Transactions of the ASAE, St. Joseph, v.38, n.3, p.669-674, 1995.

Wiermann, C.; Way, T.R.; Horn, R.; Bailey, A.C; Burt, E.C. Effects of various dynamics loads on stress and strain behavior of a Norfolk sandy loam. Soil \& Tillage Research, Amsterdam, v.50, p.127-135, 1999.

Wood, R.K; Burt, E.C. Thrust and motion resistance from soiltire stress measurements. Transactions of the ASAE, St. Joseph, v.30, n.5, p.1288-1292, 1987.

Wood, R.K., Burt, E.C; Johnson, C.E. Dynamic load effects on thrust components along the soil-tire contact zone. Transaction of the ASAE, St. Joseph, v.34, n.1, p.43-6, 1991. 